\title{
Occupational Hand Eczema among Cement users in Nepal
}

\section{Abstract:}

Background: Occupational dermatitis among cement workers is a major occupational health concern and skin contact with cement has been associated with contact dermatitis, which ranges from cement burns to cumulative irritant contact dermatitis. Objective: The objective of this study was to investigate the prevalence and severity of occupational cement contact dermatitis amongst cement workers in Nepal which is the first of its kind. Methods: A cross sectional descriptive study amongst patients in construction site and hardware shops within the Kathmandu valley were selected. A structured questionnaire was used to evaluate the demographic data and work-related activities of these cement workers. A complete skin examination was conducted and skin manifestations were assessed by a dermatologist. The data collected was compiled and appropriate statistical tools was used to find out the significance of variables. Result: Out of the total number of workers screened 164/377 (43.50\%) had hand contact dermatitis. There were males $148(90.2 \%)$ and females16 (9.8\%) and the age ranged from 15-51 years ( mean 27.41 \pm 7.68 years).The duration of the disease ranged from 1-360 months (median 36 months $(I Q R=60)$. The most common site of lesion was palms $(62.8 \%)$ followed by tip of the fingers in $39.0 \%$ patients and the most common morphology of the lesion was erythema seen in $59.1 \%$ followed by scaling seen in $51.8 \%$ patients. Conclusion: The issue of contact and irritant hand eczema amongst cement workers in Nepal has had a considerable morbidity. Identification of these patients with adequate treatment, test of the suspected allergens and counseling could further help the patients involved.

Key Words: Cement, eczema, contact dermatitis, Nepal.
Sabina Bhattarai', Rohit Murarka', Sumed Mishra', Astha Nepal', Sunil Kumar Joshi ${ }^{1}$

Kathmandu Medical College, Sinamangal, Kathmandu, Nepal

Corresponding Author: Dr. Sabina Bhattarai Email: sabeenab@gmail.com

C) 2015 IJOSH All rights reserved.

\section{Introduction}

Hand eczema is a common distressing condition giving rise to a lot of emotional and physical morbidity. [1] The term hand eczema $(\mathrm{HE})$ implies that the dermatitis is largely confined to the hands with only minor involvement of the other areas. [2] The reported prevalence of $\mathrm{HE}$ in the general population is estimated to be about $2-10 \%$ 2and it accounts for $21-34 \%$ of all types of eczema.[3]

Occupational dermatitis among cement workers is a major occupational health concern.[4] Skin contact with cement has been associated with irritant contact dermatitis, which ranges from cement burns to cumulative irritant contact dermatitis. Cement burns cause an acute ulceration [5] most frequently seen in new and untrained cement workers. In non-sensitized workers who are exposed to cement on a regular basis, cumulative irritant contact dermatitis may result.[6] some parts of the subcontinent. Though the agricultural workforce is by far the major work forcing the third world countries, its work organization has not received much attention.

With urbanization rapidly going in the capital and multiple high rise buildings coming up the actual prevalence of occupational dermatitis and specially hand eczema is not recorded. No data related to such can be found on the literature on extensive on line search. This study is the first of its kind related to the prevalence and severity of occupational dermatoses in cement workers with regular exposure to cement in Nepal.

\section{Methods}

A cross sectional descriptive study amongst patients 377 (95\% $\mathrm{Cl}$ ) in construction site and hardware shops dealing with cement within the valley for sampling convenience was selected from Dec 2014 - Nov 2015. A structured questionnaire was used 
to evaluate the demographic data and work-related activities of these cement workers. A complete skin examination was conducted and skin manifestations was assessed by a consultant dermatologist. Other skin diseases involving the hand such as infective dermatitis, dermatophytide, eczematous drug reactions, psoriasis were excluded by history and clinical examination. Camps were also conducted in the areas on a regular basis with informed notice, screening of the workers were done and then offered medicine and other treatment as and when needed.

A detailed survey was thus carried out to investigate the prevalence, causal agents, duration of the work exposure in this community. The data collected was compiled and appropriate statistical tools was used to find out the significance of variables.

\section{Result}

Out of the total number of workers screened 164/377 (43.50\%) had hand contact dermatitis. There were males $148(90.2 \%)$ and females16 (9.8.\%) and the age ranged from 15-51 years (mean $27.41 \pm 7.68$ years). The duration of the disease ranged from 1-360 months (median 36months (IQR=60).

Table1: Demographic Details of the patients

\begin{tabular}{|l|l|}
\hline \multicolumn{2}{|c|}{ Parameters } \\
\hline Male & $148(90.2 \%)$ \\
\hline Female & $16(9.8 \%)$ \\
\hline Age & \\
\hline Range & $15-51$ years \\
\hline Mean & $27.41 \pm 7.68$ years \\
\hline Duration of Disease & \\
\hline Range & $1-360$ months \\
\hline Median & 36 months (IQR=60) \\
\hline
\end{tabular}

Table 2 shows the age wise distribution of the patients.

\begin{tabular}{|lcc|}
\multicolumn{1}{r|}{ Age group } & Number & Percentage(\%) \\
\hline Less than 20 & 38 & 23.2 \\
\hline $21-30$ & 79 & 48.2 \\
\hline $31-40$ & 40 & 24.4 \\
\hline $41-50$ & 6 & 3.7 \\
\hline More than 50 & 1 & 0.5 \\
\hline
\end{tabular}

The most common site of lesion was palms (62.8\%) followed by tip of the fingers in $39.0 \%$ patients (Figure 1)and the most common morphology of the lesion was erythema seen in $59.1 \%$ followed by scaling seen in $51.8 \%$ patients. (Figure 2)
Figure 1: Site of lesions in patients having hand eczema amongst cement users

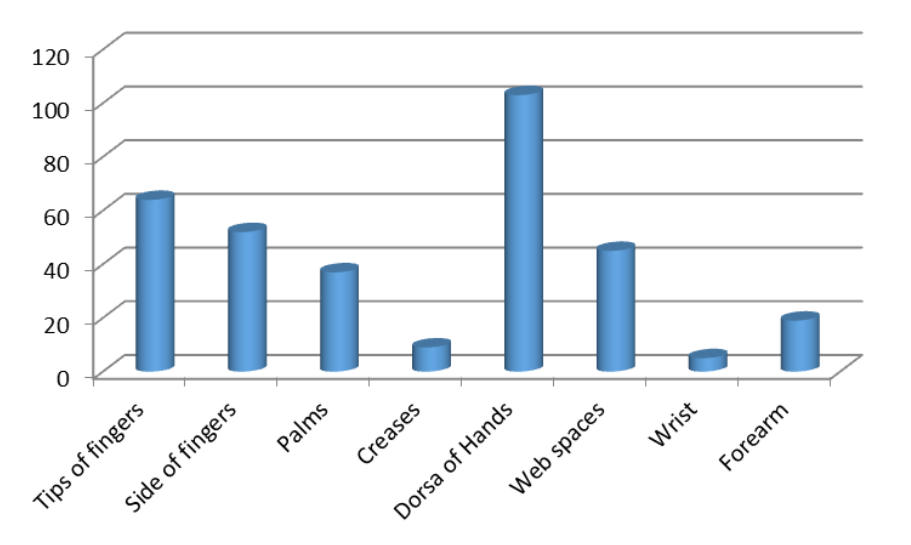

Figure 2: Morphology of lesions in patients having hand eczema amongst cement users

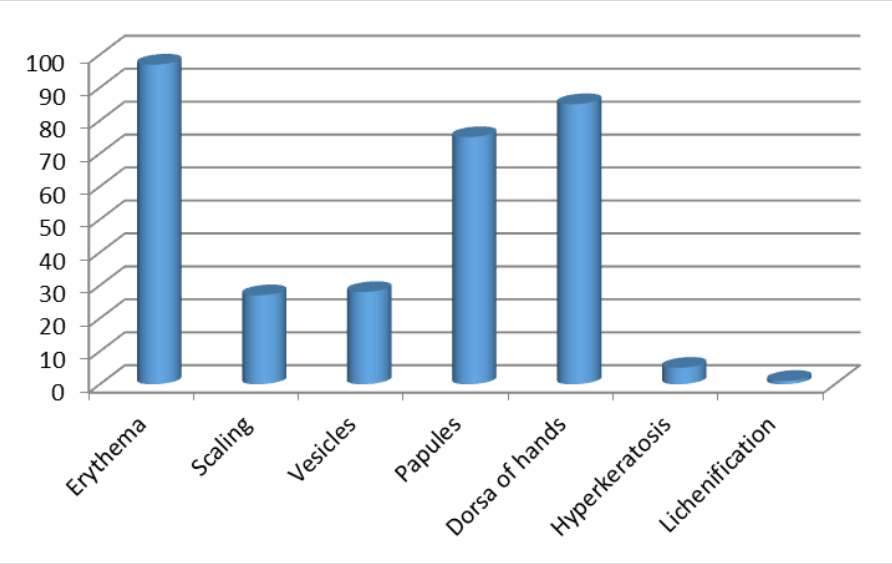

\section{Discussion}

Occupational contact dermatosis is the most significant and frequent dermatoses among all occupational skin diseases.[7] Skin in contact with cement has been associated with irritant cement contact dermatitis and allergic cement contact dermatitis. Cement contains the following substances: silicon dioxide $\left(\mathrm{SiO}_{2}\right)$, aluminium oxide $\left(\mathrm{Al}_{2} \mathrm{O}_{3}\right)$, iron oxide $\left(\mathrm{FeO}_{3}\right)$, magnesium oxide $(\mathrm{MgO})$, sulfur dioxide $\left(\mathrm{SO}_{2}\right)$ and calcium oxide $(\mathrm{CaO})$. When calcium oxide comes into contact with water, it becomes calcium hydroxide $\left(\mathrm{Ca}(\mathrm{OH})_{2}\right)$, which is a highly alkaline substance, with a $\mathrm{pH}$ value of $11-13$. It is a very strong irritant to the skin, and may sometimes produce skin erosion and even skin necrosis. [8] The common allergens affecting cement workers are: epoxy resin, colophony, formaldehyde, nickel, rubber gloves and cobalt, but the worst offender is hexavalent chromium.[9] Cement workers' hands are regularly in contact with cement, so once they suffer from hand contact dermatitis as a result of exposure to cement, they are susceptible to recurrence and complete recovery is very difficult [10]which may compromise their work efficiency.

The In this study $83.5 \%$ of cement workers were over the age of 21-30 years with a mean around 27 years (Table 1 ) which was 
slightly less as compared by the study done by Guo et all [11] and Sharma et all [12].

Association of atopy in patients with and eczema has been well documented. Our study found a prevalence of atopy in 16(9.8\%). Patients with atopy have diminished barrier function which could lead to more cumulative irritant dermatitis.

The commonest site affected were the dorsum of the hand seen in $103(62.8 \%)$ patients followed by tips of the fingers in 64 $(39.2 \%)$ (Figure 1). This result has been shown to be comparable to the studies done in India as reported by Sharma et all.[11] The most possible reason why palms were less affected than other parts of the hand could be the pattern of work done. Most of these workers were seen carrying cement blocks and mixing cements without wearing gloves and palms being more thicker could result in the less irritant reactions as compared to the dorsum of the hand.

Although a large number of studies on this subject has been published in the western world, it was difficult to compare the results because the patient selection, study purposes, and methodology used for analysis varied considerably. In contrast to the developed world, there has been no attempt to evaluate the magnitude of this problem with very less supportive evidence.

Morphologically erythema was seen in $97(59.1 \%)$ patients while hyperkeratotis plaques were the second most common presentation seen in $85(51.8 \%$ ) followed by papules in $75(45.7 \%)$ patients. The morphology suggests again the cumulative irritant damage to the skin. Acute reactions were seen in very less patients with vesiculation in $5(3.0 \%)$ patients. Our study found more irritant hand eczema as compared to the allergic contact dermatitis.

\section{Conclusion}

There are no studies in Nepal which shows the actual prevalence of occupational Hand eczema affecting persons working in the construction sites or people dealing with cement and other irritants in hard ware shops. Workplace safety guidelines are less strictly supervised in many developing countries, including Nepal.This study helped us to assess the magnitude of the problem and since it is just a base line cross sectional survey, further research can be planned to see the allergens amongst the persons suspicious of contact dermatitis amongst the cement workers.

Limitation of the Study: As this is a preliminary study, the actual data were unknown. We plan to do the patch test on subsequent visits to workers suspected of having cement allergy using the standard allergy kit as approved by the contact dermatitis forum of India.

\section{Acknowledgment}

The authors sincerely thank the workers and employers for their participation and cooperation. A special thank you to Bicky Hardware in Jadibuti,Gongabu,Balkhu,Sukedhara and Sallaghari.
Construction sites at Sanepa, labour construction road of Pepsi-cola, Jadibuti sector and the Jadagamba tower construction phase in Sallaghari deserves special acknowledgment.

\section{References}

1. Census Handa S, Kaur I, Gupta T, Jindal R. Hand eczema: Correlation of morphologic patterns, atopy, contact sensitization and disease severity. Indian $\mathrm{J}$ Dermatol Venereol Leprol 2012 ;78:153-158

2. Epstein E. Hand Dermatitis: Practical management and current concepts. J Am Acad Dermatol 1984; 10: 395-424.

3. Clark RAF, Hopkins TT. The other eczemas. In: Moschella SL, Hurley HJ, Dermatology 3rd Ed Vol 1 Philadelphia, WB Saunders Company, 1992: 493- 498.

4. Wang BJ, Wu JD, Sheu SC, Shih TS, Chang HY, Guo YL et al. Occupational hand dermatitis among cement workers in Taiwan. J Formos Med Assoc. 2011 Dec;110(12): 775-759

5. Mc-Geown G. Cement burns of the hand. contact Dermatitis 1984; 10: 246.

6. Coenraads PJ, Nater JP, Jansen HA, Lantinga $H$. Prevalence of eczema and other dermatoses of the hands and forearms in construction workers in the Netherlands. Clin Exp Dermatol 1984; 9: 149-158

7. Uter W, Ruhl R, Pfahlberg A, Geier J, Schnuch A, Gefeller O. Contact allergy in construction workers: Results of a multifactorial analysis. Ann Occup Hyg. 2004;48:21-27.

8. Avnstorp, C. Cement eczema. An epidemiological intervention study. Acta Dermato-Venereol Supple. 1992; 179: $1-22$

9. Marks, J.G., Elsner, P., and DeLeo, V. Contact and occupational dermatology. Mosby Inc., Missouri, USA; 2002 : 344-346

10. Fregert, S. Occupational dermatitis in a 10-year material. Contact Dermatitis. 1975; 1: 96-107

11. Guo YL, Wang BJ, Yeh KC, Wang JC, Kao HH, Wang MT, et al. Dermatoses in cement workers in southern Taiwan. Contact Dermatitis. 1999;40:1-7

12. Sharma N.Occupational allergic contact dermatitis among construction workers in India. Indian J Dermatol. 2009 Apr-Jun; 54(2): 137-141. 